\title{
Analisa Produktivitas Pekerjaan Pracetak Segmental-Box Girder, Proyek Bogor Outer Ring Road Seksi II A
}

\author{
Prita Herdianti $^{1)}$ dan Johan Budiman ${ }^{2 *}$ \\ Jurusan Teknik Sipil, Fakultas Teknik, Universitas Islam Syekh Yusuf, Jl. Mulana Yusuf No.10 Tangerang \\ Banten 15118, Indonesia \\ 1) prita1907@gmail.com \\ 2) johanbudiman061@gmail.com
}

\begin{abstract}
Abstrak. Pada produksi Pekerjaan Pracetak Segmental - Box Girder Proyek Bogor Outer Ring Road Seksi II A terdapat keunikan sistem manufaktur yang biasanya memproduksi berdasarkan jumlah target yang akan dihasilkan namun pada kasus ini produksi dilakukan secara kontinu untuk menghasilkan 1 span yang terdiri dari berbagai jenis segment box grider. Variasi urutan produksi box girder inilah yang akan berpengaruh terhadap durasi pekerjaan 1 span. Untuk mengurangi waste diperlukan suatu perencanaan dan analisa konstruksi yang baik agar waktu siklus produksi menjadi lebih singkat. Perencanaan yang baik didasarkan pada suatu simulasi berulang hingga didapat suatu unit produktifvitas sebagai acuan pada tahap selanjutnya. Hasil simulasi sebanyak 300 kali menunjukan 1 span yang terdiri dari 18 segment box girder dapat diproduksi selama 21 hari dengan asumsi tidak terjadi banyak delay. Dalam hal mempercepat proses produksi digunakan 5 cetakan sehingga dalam 21 hari dapat memproduksi sebanyak 5 span.
\end{abstract}

Kata kunci: produktivitas, box girder, perencanaan

Abstract. [Productivity Analysis of Segmental Preprint Work - Box Girder, Bogor Outer Ring Road Project Section II A]. In Practice Segmental Preparing Work - Box Girder Bogor Outer Ring Road Project Section II A there is a uniqueness of manufacturing systems that usually produce based on the number of targets to be produced but in this case the production is done continuously to produce 1 span consisting of various types of segment box grider. Variations in the order of production of this girder box that will affect the duration of work 1 span. Good planning is based on a repeating simulation until a productivity unit is obtained as a reference in the next stage. Simulation results as much as 300 times shows a span consisting of 18 segments box girder can be produced for 21 days assuming no delay occurs. In order to speed up the production process used 5 prints so that in 21 days can produce as many as 5 span.

Keywords: productivty, box grider, planning

\section{Pendahuluan}

\section{Latar Belakang}

Kebutuhan infrastruktur ditanah air terus meningkat, sering dengan pertumbuhan tersebut perushaan konstruksi dituntut agar mampu menghasilkan produk sesuai dengan kebutuhan dengan biaya dan waktu yang efisien. Namun disisi lain Industri konstruksi memiliki masalah dengan proses produksi yang tidak efisien. Banyak kegiatan yang menggunakan sumberdaya namun tidak memberikan nilai tambah pada produk akhir (waste). Untuk mengurangi waste diperlukan suatu perencanaan dan analisa konstruksi yang baik agar waktu siklus produksi menjadi lebih singkat, dan pekerja termotivasi dan berpartisipasi aktif sehingga biaya terhadap kualitas produk berkurang.

\section{Tujuan}

Merencanakan dan menganalisa operasi pracetak segmental box girder yang optimum yang ditinjau dari segi waktu dan sumber daya yang digunakan.

\section{Ruang Lingkup}

Penelitian ini dilakukan dengan batasan-batasan masalah sebagai berikut:

1. Penelitian dan studi kasus hanya dilakukan pada Pracetak Segmental Box Girder PT. 
Wijaya Karya yang digunakan pada proyek Bogor Ring Road

2. Penelitian hanya membahas tentang perencanaan dan analisa operasi Pracetak Segmental Box Girder yang optimum ditinjau dari segi waktu dan sumber daya.

\section{Bahan dan Metode:}

Metode penelitian yang dipakai dalam penelitian adalah metode survey lapangan terhadap operasi pracetak segmental box girder. Teknik pengumpulan data dilakukan dengan wanwancara dan pengamatan langsung. Data pengamatan operasi pracetak segmental box girder yang didapat selanjutnya dilakukan identifikasi sumber daya yang digunakan, work task dan durasi dari masing-masing work task untuk selanjutnya dilakukan pemodelan dengan menggunakan webcyclone dan selanjutnya dilakukan analisis produktivitas. Analisis produktivitas dimaksudkan guna mendapatkan sumber daya optimal dalam proses produksi segmental box girder. Metode penilitian yang dilakukan untuk mencapai tujuan penelitian secara sistematis seperti yang terlihat pada Gambar 1.

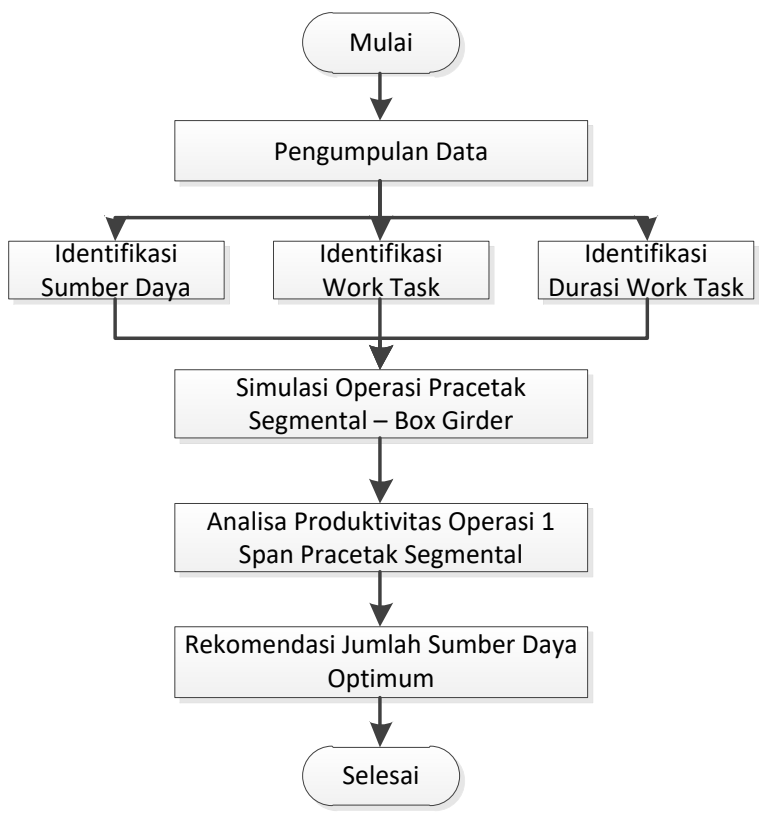

Gambar 1. Bagan Alur Penelitian

\section{Hasil dan Pembahasan \\ Data Produksi}

1. Tipe Segmental Box Girder
Pada proyek BORR digunakan 4 tipe segmental box girder yaitu Tipe Normal, Tipe Diaphragma, Tipe EJ-Diaphragma dan Tipe EJ-A seperti yang terlihat pada Gambar 2.

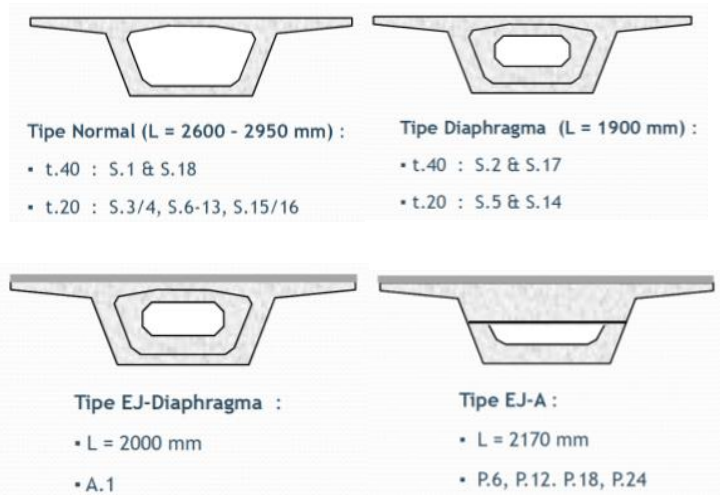

Gambar 2. Tipe Box Girder

Jumlah segmental box girder per bentang adalah 18 box girder dengan distribusi seperti yang terlihat pada Gambar 3.

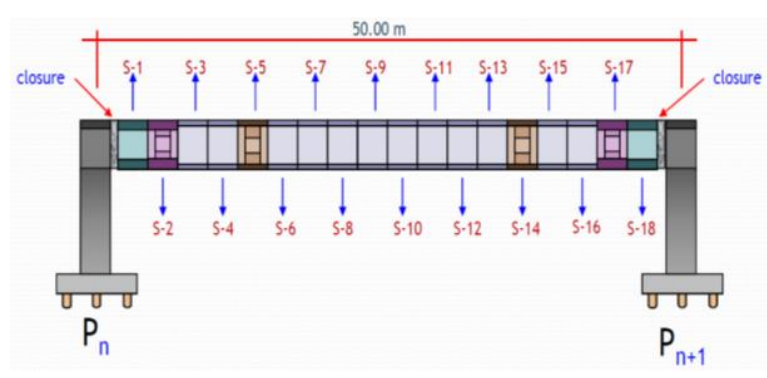

Gambar 3. Distribusi Segmental - Box Girder per Bentang

Urutan produksi bentang umumnya adalah: 1 Normal $\rightarrow 1$ Diaphragma $\rightarrow 2$ Normal $\rightarrow 1$ Diaphragma $\rightarrow 8$ Normal $\rightarrow 1$ Diaphragma $\rightarrow 2$ Normal $\rightarrow$ 1Diaphragma $\rightarrow 1$ Normal.

\section{Identifikasi Proses Pracetak \\ a. Work Task}

Work task adalah aktivitas pekerjaan dalam operasi pracetak segmental - box girder yang akan dimodelkan dalam simulasi operasi konstruksi. Work task dalam operasi pracetak cukup banyak namun, dalam penelitian ini beberapa work task yang ditinjau yaitu:

- Setting Cetakan

- $\quad$ Setting Normal/ Diaphragma inner

- Final Set

- Pouring

- Couring

- Reposition 


\section{b. Sumber Daya}

\section{- Cetakan}

Cetakan berfungsi sebagai jalur produksi 1 span secara seri atau menerus

- Data Set

Data set adalah data yang diperoleh dari design cast untuk dapat memproduksi segmen box girder

\section{- Innerform}

Innerform adalah bagian dari cetakan yang berfungi membentuk rongga box girder untuk membentuk box girder tertentu. Setiap cetakan terdapat satu buah innerform. Innerform box girder seperti ditunjukan pada Gambar 4.

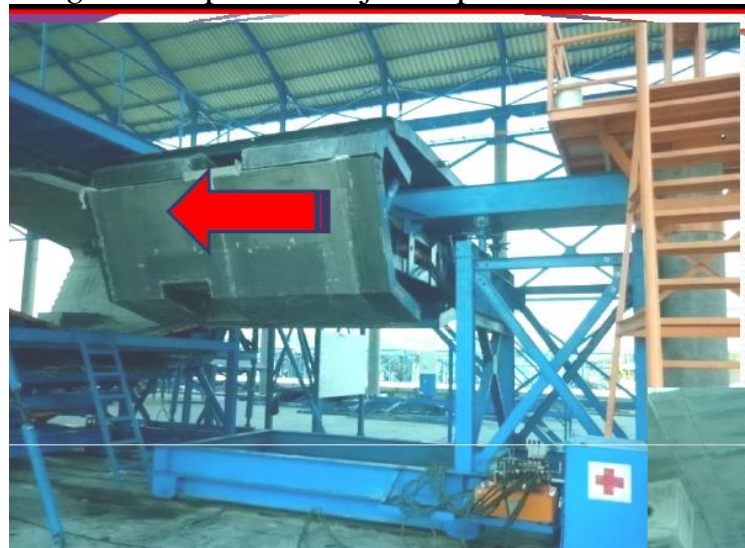

Gambar 4. Setting Innerform

\section{c. Waktu}

Setiap work task yang diamati dicatat durasi penyelesaian masing-masing work task.

\section{Proses Pracetak Segmental}

Dalam proses pracetak box girder proyek BORR, PT. Wijaya Karya menggunakan lima buah cetakan. Dimana masing-masing bekerja secara seri tidak saling ketergantungan antara yang satu dan yang lain. Pada setiap cetakan dilengkapi dengan satu buah innerform. Setiap cetakan menangani 1 span. Urutan pracetakan segmental box girder seperti ditunjukan pada Gambar 5

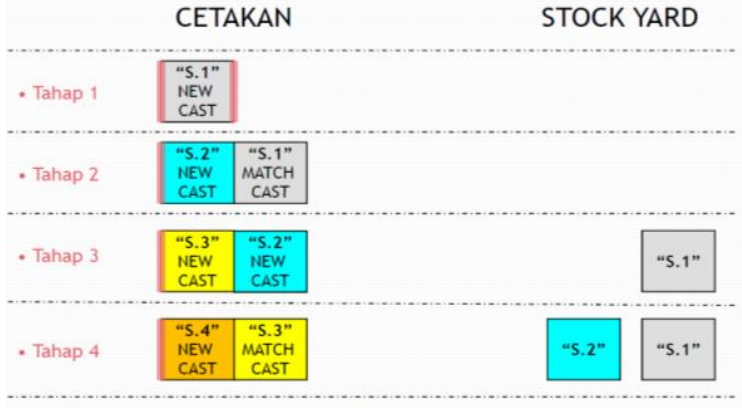

政

Gambar 5. Urutan Produksi Box Girder
Pada tahap 1 cetakan mulai memproduksi box girder "S.1". setelah mengeras, segmental box girder "S1" digunakan sebagai matchcast untuk box girder "S.2" dan box girder "S.2" digunakan sebagai matchcast box girder "S.3" dan box girder "S.1" dibawa ke stockyard. Urutan ini terus berlansung hingga menghasilkan 18 box girder atau satu span.

\section{Metode Pekerjaan Pembuatan Box Girder pada casting yard}

\section{Setting Cetakan (Formwork)}

Pekerjaan pembuatan box girder dimulai dengan pekerjaan persiapkan cetakan (form work). Satu set cetakan utama formwork terdiri dari beberapa bagian yang merupakan rangkaian dari bulk head, wing form, soffit table, transfer chart serta inner form (Normal \& Diaphragma). Rangkaian cetakan ini dirakit (setting) sehingga membentuk 1 set cetakan lengkap workform.

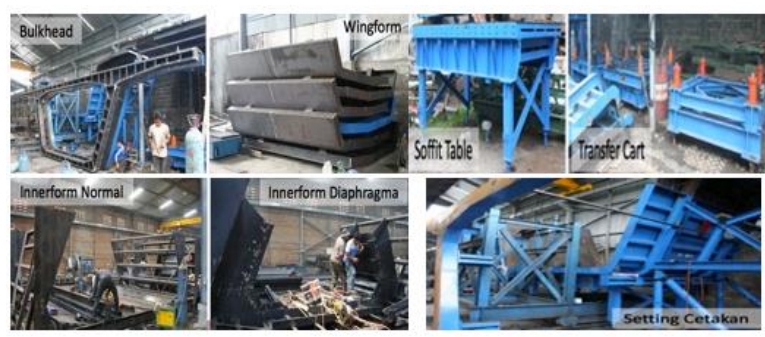

Gambar 6. Setting Cetakan

Setelah cetakan diset maka tahapan selanjutnya adalah:

- Install Besi tulangan dan Ducting Tendon dalam Cetakan Sementara (Rebar Jig). Perakitan besi tulangan dan ducting tendon dilakukan di area pabrikasi dengan menggunakan cetakan sementara (Rebar Jig)

- $\quad$ Setting Rakitan Tulangan kedalam Cetakan (Formwork). Besi tulangan yang telah dirakit diangkat dari Rebar Jig kemudian di install pada cetakan formwork yang telah dipersiapkan setting sebelumnya.

- Setting Ducting tendon bawah. Setelah rakitan tulangan terpasang didalam cetakan formwork maka dilakukan setting ducting tendon bawah untuk menentukan elevasi yang tepat.

\section{Setting Cetakan Bagian Dalam (Innerform)}

Setelah pengaturan tendon dilakukan maka langkah selanjutnya adalah melakukan pengaturan (setting) cetakan bagian dalam 
(innerform). Setiap cetakan utama (formwork) memiliki 1 buah innerform yang dapat dimodifikasi untuk membuat setiap unit segment box girder (Normal \& Diaphragma). Setting cetakan bagian dalam innerform dilakukan dengan cara mengatur dan memasukan innerform kedalam formwork yang telah terpasang tulangan sebelumnya.

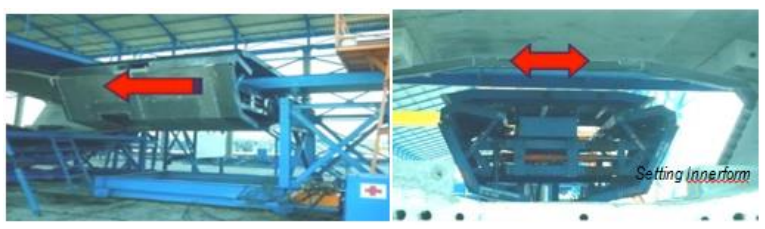

Gambar 7. Setting Innerform

\section{Final Setting}

- Setting Tendon atas dan aksesoris dan insert. Setelah innerform diinstall didalam formwok maka dilakukan setting tendon atas dan pemasangan aksesoris dan insert.

- Final Survey (pengecekan akhir) sebelum pengecoran. Pengecekan akhir dilakukan pada formwork yang telah siap (ready) untuk dicor.

\section{Pengecoran Segment Box Girder}

Pengcoran dilakukan dengan menggunakan beton K-500 (f'c $\left.=415 \mathrm{~kg} / \mathrm{cm}^{2}\right)$ dengan Slump: flow $60(5 \mathrm{~cm})$

\section{Pekerjaan Finishing dan Curing}

Pekerjaan Finishing dilakukan setelah formwork telah tercor penuh, Curing dilakukan selama 10 jam untuk setiap unit segmental box girder (Normal \& Diaphragma)

\section{Reposisiton}

Setelah pracetak unit segmental siap Yaitu apabila kuat tekan beton mencapai $50 \%$ (f'c = $210 \mathrm{~kg} / \mathrm{cm}^{2}$ ) setelah umur beton \pm 10 jam maka tahap selanjutnya adalah:

- Survey Setelah Pengecoran sebagai Data as-Built Survey data as-built dilakukan sebagai data acuan untuk pembuatan matchcast segment box girder selanjutnya.

- Buka/Longgarkan semua cetakan (Formwork)

- Selanjutnya segment box girder yang telah dikeluarkan dari cetakan diangkat dan dipindahkan dari line produksi di pabrik ke stock yard dengan menggunakan Crane dan Truck.
Setelah itu di modelkan seperti yang ditunjukan pada Gambar 8.

\section{Analisa Data}

Pada produksi segmental box grider 1 buah cetakan dengan 1 buah Innerform memproduksi secara menerus (kontinu) 1 span dari s-1 sampai dengan s-18. Urutan metode pekerjaan produksi 1 span box grider dan asumsi jumlah durasi yang dibutuhkan (dalam satuan jam) pada casting yard disajikan dalam Gambar 9 berikut ini.

\begin{tabular}{|c|c|c|c|c|c|c|}
\hline No. & Urutan Segmen & Tugas (Task) & $\begin{array}{c}\text { Tipe } \\
\text { Distribusi }\end{array}$ & Min & Mean & Maks \\
\hline \multirow{6}{*}{1} & \multirow{6}{*}{ Box Girder Normal } & Set Cetakan & Triangular & 5 & 6 & 8 \\
\hline & & Setting Normal & Triangular & 1,5 & 2 & 2,5 \\
\hline & & Final & Deterministik & \multicolumn{3}{|c|}{2} \\
\hline & & Cor & Triangular & 0,75 & 1 & 1,25 \\
\hline & & \begin{tabular}{|l|} 
CURING \\
\end{tabular} & Deterministik & \multirow{2}{*}{\multicolumn{3}{|c|}{10}} \\
\hline & & Reposition & Deterministik & \multicolumn{2}{|r|}{3} & \\
\hline \multirow{6}{*}{2} & \multirow{6}{*}{ Box Girder Diaphragma } & Set Cetakan & Triangular & 5 & 6 & 8 \\
\hline & & Setting Diaphragma & Triangular & 4,5 & 5 & 5,5 \\
\hline & & Final & Deterministik & \multicolumn{3}{|c|}{4} \\
\hline & & \begin{tabular}{|l|} 
Cor \\
\end{tabular} & Triangular & 0,75 & 1 & 1,25 \\
\hline & & CURING & Deterministik & \multicolumn{3}{|c|}{10} \\
\hline & & Reposition & Triangular & & 3 & \\
\hline \multirow{6}{*}{3} & \multirow{6}{*}{ Box Girder Normal (2) } & Set Cetakan & Triangular & 5 & 6 & 8 \\
\hline & & Setting Normal & Triangular & 1,5 & 2 & 2,5 \\
\hline & & Final & Deterministik & \multicolumn{3}{|c|}{2} \\
\hline & & Cor & Triangular & 0,75 & 1 & 1,25 \\
\hline & & \begin{tabular}{|l|} 
CURING \\
\end{tabular} & Triangular & & 10 & \\
\hline & & Reposition & Deterministik & \multicolumn{3}{|c|}{3} \\
\hline \multirow{6}{*}{4} & \multirow{6}{*}{ Box Girder Diaphragma } & Set Cetakan & Triangular & 5 & 6 & 8 \\
\hline & & Setting Diaphragma & Triangular & 4,5 & 5 & 5,5 \\
\hline & & Final & Deterministik & \multicolumn{3}{|c|}{4} \\
\hline & & Cor & Triangular & 0,75 & 1 & 1,25 \\
\hline & & CURING & Triangular & & 10 & \\
\hline & & Reposition & Deterministik & \multicolumn{3}{|c|}{3} \\
\hline \multirow{6}{*}{5} & & Set Cetakan & Triangular & 5 & 6 & 8 \\
\hline & & Setting Normal & Triangular & 1,5 & 2 & 2,5 \\
\hline & Boy Giter Normol $\&$ & Final & Deterministik & & 2 & \\
\hline & Box Girder Normal (8) & Cor & Triangular & 0,75 & 1 & 1,25 \\
\hline & & \begin{tabular}{|l|} 
CURING \\
\end{tabular} & Deterministik & & 10 & \\
\hline & & Reposition & Deterministik & & 3 & \\
\hline & & Set Cetakan & $\begin{array}{l}\text { Triangular } \\
\end{array}$ & 5 & 6 & 8 \\
\hline & & Setting Diaphragma & Triangular & 4,5 & 5 & 5,5 \\
\hline 6 & Box $G$ irder Dinphrom & Final & Deterministik & & 4 & \\
\hline 0 & Box Giraer Dlapiragina & Cor & Triangular & 0,75 & 1 & 1,25 \\
\hline & & \begin{tabular}{|l} 
CURING \\
\end{tabular} & Deterministik & & 10 & \\
\hline & & Reposition & Deterministik & & 3 & \\
\hline & & Set Cetakan & Triangular & 5 & 6 & 8 \\
\hline & & Setting Normal & Triangular & 1,5 & 2 & 2,5 \\
\hline 7 & Box Givder Normol(0) & Final & Deterministik & & 2 & \\
\hline 1 & Box Girder Normal (2) & Cor & Triangular & 0,75 & 1 & 1,25 \\
\hline & & CURING & Deterministik & & 10 & \\
\hline & & Reposition & Deterministik & & 3 & \\
\hline & & Set Cetakan & Triangular & 5 & 6 & 8 \\
\hline & & Setting Diaphragma & Triangular & 4,5 & 5 & 5,5 \\
\hline 8 & Box Girder Diaphragma & Final & Deterministik & & 4 & \\
\hline & & Cor & Triangular & 0,75 & 1 & 1,25 \\
\hline & & \begin{tabular}{|l|} 
CURING \\
\end{tabular} & Deterministik & & 10 & \\
\hline & & Reposition & Deterministik & & 3 & \\
\hline & & Set Cetakan & Triangular & 5 & 6 & 8 \\
\hline & & Setting Normal & Triangular & 1,5 & 2 & 2,5 \\
\hline 0 & Bor Firder Normol & Final & Deterministik & & 2 & \\
\hline 9 & Box Girder N Normal & Cor & Triangular & 0,75 & 1 & 1,25 \\
\hline & & CURING & Deterministik & & 10 & \\
\hline & & Reposition & Deterministik & & 3 & \\
\hline
\end{tabular}

Gambar 9. Distribusi Waktu Probabilitas

Pemberian waktu deterministik didasarkan pada data yang didapat dari perusahaan dan asumsi penggunaan durasi Triangular disebabkan karena tidak teridentifikasinya secara akurat resources yang 
ada oleh karena tidak meninjau langsung ke lokasi. Sehingga asumsi nilai terendah jika terjadi resource lebih dari yang dibutuhkan sehingga pekerjaan lebih cepat dan yang sudah steady, dapat dilihat pada grafik Gambar 11.

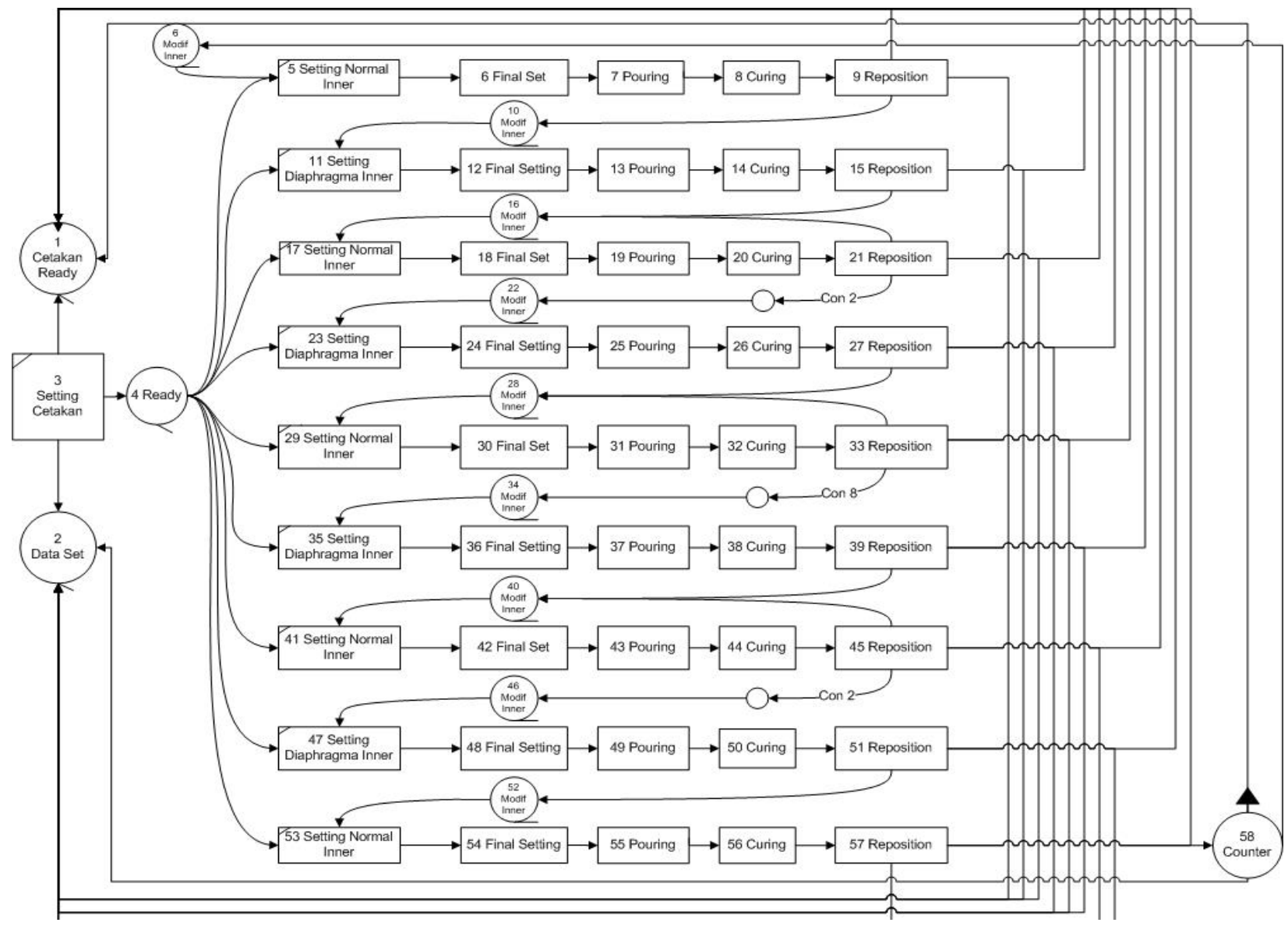

Gambar 8. Tahapan pekerjaan pracetak Segmental - Box Girder dengan pemodelan WEBCYCLONE

nilai durasi tertinggi jika pekerjaan tersebut mengalami delay.

Tahapan selanjutnya adalah melakukan pemodelan pada software Disco lalu menjalankan simulasi (Run 300 cycles) menggunakan Webcyclone pada situs http://cyclone.ecn.purdue.edu:8080/WebCYCL ONE/Cyclone.jsp dengan mengupload model yang telah dibuat sebelunya dengan software Disco ver.1.0 maka didapat tabel produktivitas 1 span (18 box grider) seperti pada Gambar 10.

Dari Gambar 10 diperoleh produktivitas 0,002185 span/ jam untuk 300 siklus, ini berarti untuk bisa memproduksi 1 span yang terdiri atas 18 segmen box grider dengan 4 box tipe Diaphragma dan 14 box tipe Normal diperlukan waktu produksi selama 20,83 hari $=21$ hari. Waktu produksi tersebut diasumsikan sebagai kegiatan yang sebagian besarnya dilakukan secara menerus (kontinu) tanpa gangguan. Kondisi tersebut merupakan kondisi simulasi

\begin{tabular}{|c|c|c|}
\hline \multicolumn{3}{|c|}{ PRODUCTIVITY INFORMATION } \\
\hline Total Sim. Time Unit & Cycle No. & Productivity (per time unit) \\
\hline 137328,5 & 300 & 0,002184543 \\
\hline \multicolumn{3}{|c|}{ PRODUCTIVITY INFORMATION } \\
\hline Sim. Time & Cycle No. & Productivity Per Time Unit \\
\hline 450,7 & 1 & 0,002219 \\
\hline 917,5 & 2 & 0,00218 \\
\hline 1378,9 & 3 & 0,002176 \\
\hline 1834,9 & 4 & 0,00218 \\
\hline 2291,8 & 5 & 0,002182 \\
\hline 2744 & 6 & 0,002187 \\
\hline 3201 & 7 & 0,002187 \\
\hline 3650,8 & 8 & 0,002191 \\
\hline 4098,3 & 9 & 0,002196 \\
\hline 4559 & 10 & 0,002193 \\
\hline 5007,9 & 11 & 0,002197 \\
\hline 5462,7 & 12 & 0,002197 \\
\hline 5919,2 & 13 & 0,002196 \\
\hline 6376,3 & 14 & 0,002196 \\
\hline 6839,6 & 15 & 0,002193 \\
\hline
\end{tabular}

Gambar 10. Siklus Produksi 1 Span 
cetakan dan data set merupakan resource kunci yang terus menerus aktif dalam proses produksi.

Sedangkan Inner form yang pada

\begin{tabular}{|c|c|c|c|c|c|c|c|c|c|}
\hline \multicolumn{10}{|c|}{ CYCLONE PASSIVE ELEMENTS STATISTICS INFORMATION } \\
\hline Type & No. & Name & $\begin{array}{l}\text { Average } \\
\text { Units Idle }\end{array}$ & $\begin{array}{l}\text { Max. Idle } \\
\text { Units }\end{array}$ & $\begin{array}{l}\text { Times not } \\
\text { empty }\end{array}$ & $\%$ Idle & $\begin{array}{l}\text { Total Sim } \\
\text { Time }\end{array}$ & $\begin{array}{c}\text { Average } \mathrm{Wt} \\
\text { Time }\end{array}$ & Units at end \\
\hline QUEUE & 1 & Cetakan Available & 0 & 1 & 0 & 0 & 137328,5 & 0 & 0 \\
\hline QUEUE & 2 & Data Set & 0 & 1 & 0 & 0 & 137328,5 & 0 & 0 \\
\hline QUEUE & 4 & Ready & 0 & 1 & 0 & 0 & 137328,5 & 0 & 0 \\
\hline QUEUE & 6 & Mod Inner & 0 & 1 & 1896,3 & 1,38 & 137328,5 & 6,3 & 1 \\
\hline QUEUE & 16 & Mod Inner & 0 & 1 & 1898 & 1,38 & 137328,5 & 6,3 & 0 \\
\hline QUEUE & 22 & Mod Inner & 0 & 1 & 1902,4 & 1,39 & 137328,5 & 6,3 & 0 \\
\hline QUEUE & 28 & Mod Inner & 0 & 1 & 1915,6 & 1,39 & 137328,5 & 6,4 & 0 \\
\hline QUEUE & 34 & Mod Inner & 0 & 1 & 1887 & 1,37 & 137328,5 & 6,3 & 0 \\
\hline QUEUE & 40 & Mod Inner & 0 & 1 & 1899,3 & 1,38 & 137328,5 & 6,3 & 0 \\
\hline QUEUE & 46 & Mod Inner & 0 & 1 & 1878,7 & 1,37 & 137328,5 & 6,3 & 0 \\
\hline QUEUE & 52 & Mod Inner & 0 & 1 & 1910 & 1,39 & 137328,5 & 6,4 & 0 \\
\hline
\end{tabular}

Gambar 12. Siklus Produksi 1 Span

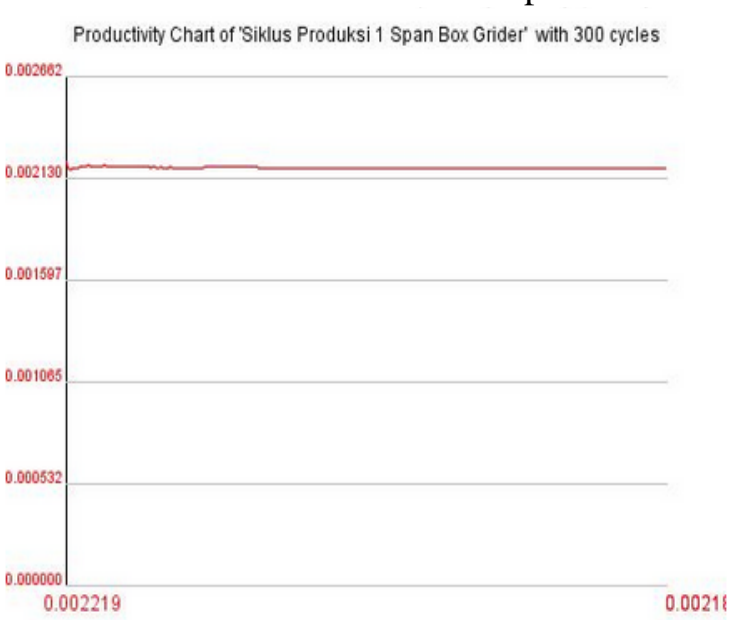

Gambar 11. Grafik Siklus Produksi 1 Span

Dari grafik produktivitas di atas dapat dilihat bahwa pada siklus pertama, didapat produktivitas sebesar 0.002219 per jamnya untuk menyelesaikan 1 span. Pada siklus kedua terjadi penurunan produktivitas sebesar 0.00001, karena perhitungan counter diletakkan sebelum resource Innerform kembali ke posisi awal Modifikasi Inner sehingga ada pertambahan waktu untuk kembalinya resorce tersebut pada siklus berikutnya. Pada siklus ini resource Cetakan dan Innerform berperan sebagai pasangan resource utama yang melayani produksi keseluruhan segmen untuk 1 span, sehingga dalam satu siklus operasi dengan siklus operasi berikutnya didapat nilai produktivitas yang hampir konstan. Untuk dapat melihat seberapa sibuk masing-masing resource yang tersedia maka pada Gambar 12 dapat menunjukan bahwa resource cetakan dan data set tidak memiliki presentase idle time karena aktualnya juga dipakai secara menerus, namun pada tabel menunjukan bahwa Inner form memiliki waktu tunggu untuk dapat masuk pada task selanjutnya yaitu setting normal atau setting diaphragma selama 6 jam serta memiliki presentase idle time dikarenakan proses setting cetakan sebelumnya.

\section{Kesimpulan}

Hasil simulasi sebanyak 300 kali menunjukan 1 span yang terdiri dari 18 segment box dapat diproduksi selama 21 hari dengan asumsi tidak terjadi banyak delay. Dalam hal mempercepat proses produksi digunakan 5 cetakan sehingga dalam 21 hari dapat memproduksi sebanyak 5 span. Jika dibandingkan dengan data aktual produksi maka terjadi keterlambatan dari rencana sebelumnya. Hal ini tidak dapat di analisa sensitivitas lebih lanjut dikarenakan tidak dilakukannya pengamatan secara langsung dilokasi untuk mengetahui variable tambahan apa yang berfungsi sebagai resource dan dapat menyebabkan delay akibat perubahan yang terjadi.

Pada kasus ini tidak dilakukan analisa sensitivitas, dikarenakan 5 cetakan yang digunakan berfungsi secara paralel namun proses produksi 1 span dilakukan secara seri. Sehingga 1 cetakan, data, dan Inner Form yang digunakan tetap untuk memproduksi 1 span secara kontinu.

\section{Daftar Pustaka}

Abduh, M. (2014). Materi Kuliah SI-5154 Perencanaan dan Analisa Operasi Konstruksi. Institut Teknologi Bandung. 
Halpin, D.W. \& Leland S. Riggs. (1992). Planning and Analysis Of Construction Operations, Willey: New York.

http://cyclone.ecn.purdue.edu:8080/WebCYCL ONE/Cyclone.jsp 